University of Nebraska - Lincoln

DigitalCommons@University of Nebraska - Lincoln

Faculty Publications: Department of Entomology

Entomology, Department of

7-19-2006

\title{
Comparative Efficiency of Six Stable Fly (Diptera: Muscidae) Traps
}

David B. Taylor

USDAĐARS Midwest Livestock Insects Research Laboratory, dave.taylor@ars.usda.gov

Dennis Berkebile

USDA-ARS, DENNIS.BERKEBILE@ars.usda.gov

Follow this and additional works at: https://digitalcommons.unl.edu/entomologyfacpub

Part of the Entomology Commons

Taylor, David B. and Berkebile, Dennis, "Comparative Efficiency of Six Stable Fly (Diptera: Muscidae) Traps" (2006). Faculty Publications: Department of Entomology. 28.

https://digitalcommons.unl.edu/entomologyfacpub/28

This Article is brought to you for free and open access by the Entomology, Department of at DigitalCommons@University of Nebraska - Lincoln. It has been accepted for inclusion in Faculty Publications: Department of Entomology by an authorized administrator of DigitalCommons@University of Nebraska - Lincoln. 


\title{
Comparative Efficiency of Six Stable Fly (Diptera: Muscidae) Traps
}

\author{
DAVID B. TAYLOR ${ }^{1}$ AND DENNIS BERKEBILE
}

USDA-ARS Midwest Livestock Insects Research Laboratory, Department of Entomology, University of Nebraska, Lincoln, NE 68583

\section{J. Econ. Entomol. 99(4): 1415-1419 (2006)}

\begin{abstract}
Five adhesive traps and the Nzi cloth-target trap were compared to determine their trapping efficiency and biases for stable flies, Stomoxys calcitrans (L.) (Diptera: Muscidae). Two configurations of the BiteFree prototype trap, constructed of polyethylene terephthalate, were most efficient for trapping stable flies, whereas the EZ trap was least efficient. The two Alsynite traps, Broce and Olson, were intermediate to the BiteFree prototype and EZ traps. All adhesive traps collected a ratio of approximately two males for each female. Approximately $50 \%$ of the flies collected on the adhesive traps, both male and female, were blood fed, and $20 \%$ were vitellogenic. The Nzi trap collected an older component of the stable fly population, $81 \%$ blood fed and $62 \%$ vitellogenic, but it was much less efficient than the adhesive traps. The effectiveness of the BiteFree prototype trap indicates that materials other than Alsynite are attractive to stable flies.
\end{abstract}

KEY WORDS traps, Nzi trap, Broce trap, Olson trap, stable fly

Stable flies, Stomoxys calcitrans (L.) (Diptera: Muscidae), are among the most important arthropod pests of cattle in North America. Kunz et al. (1991) estimated the adverse impact of stable flies on the cattle industry to be $\$ 432$ million/yr. This estimate was limited to dairy and feedlot animals because stable flies were not considered to be pests of pasture animals at that time. During the past $20 \mathrm{yr}$, stable flies have emerged as major pests of pasture cattle (Campbell et al. 2001). Based upon the per animal loss estimates of Campbell et al. (2001), i.e., \$33.26; the number of cattle slaughtered in the United States, 32.4 million in 2005 (USDA-NASS 2006); and assuming that one-half of these cattle were exposed to at least the moderate levels of flies observed by Cambell et al. (2001), one can conservatively estimate an economic loss in excess of $\$ 500$ million/yr to pasture cattle in the United States. This cost, combined with their impact on feeder and dairy cattle, increases the cost of stable flies to the cattle industry to nearly $\$ 1$ billion/yr in North America. This makes stable flies the most economically important arthropod pest of cattle in the United States.

Stable flies are also serious pests of humans and companion animals, especially dogs and horses. Their painful bites and tenacious behavior make them serious pests at recreational areas such as beaches and golf courses (Newson 1977). Although the economic impact

\footnotetext{
This article reports the results of research only. Mention of a proprietary product does not constitute an endorsement or a recommendation for its use by USDA.

${ }^{1}$ Corresponding author, e-mail: dtaylor1@unl.edu.
}

of stable flies on recreation and companion animals has not been quantified; it is considered significant.

Several factors complicate stable fly control efforts. Stable fly larvae develop in decomposing vegetative material frequently, but not necessarily, mixed with animal wastes. Documented developmental sites include greenchop residues and postharvest refuse (Hogsette et al. 1987); silage (Scholl et al. 1981, Meyer and Petersen 1983); freshwater grasses and algal mats along recreational aquatic shorelines (Simmons and Dove 1941, Pickard 1968, Williams et al. 1980); grass clippings, pet droppings, and poorly managed compost piles in urban environments (Haines 1953, Ware 1966, Broce 1993); and under large round hay bales (Hall et al. 1982) in addition to sites associated with animal wastes (Haines 1955, Skoda et al. 1991, Lysyk 1993, Skoda and Thomas 1993). Because these habitats are widespread, biologically very active, and frequently ephemeral, chemical control options are limited. Adult stable flies are strong fliers requiring large-scale or areawide efforts if they are to be successful in reducing adult fly populations. Simmons and Dove (1941) reported stable flies "biting" fishermen 19 km offshore of the Florida Panhandle. Using self-marking Alsynite traps, Hogsette and Ruff (1985) were able to detect dispersal from agricultural areas in northwestern Florida to coastal beaches, a distance of $225 \mathrm{~km}$. Several studies (Hansens 1951, Voegtline et al. 1965, Hogsette et al. 1987) describe stable fly adults annoying bathers in recreational areas with no local larval habitats found and attribute the populations to migrant adults. Finally, stable flies tend to bite on the lower legs of their hosts where insecticides and re- 
Table 1. Mean number of stable flies collected per day on six types of traps

\begin{tabular}{|c|c|c|c|c|c|c|}
\hline Trap & $\begin{array}{l}\text { Mean no. } \\
\text { flies } \pm \text { SD }\end{array}$ & $\begin{array}{l}\text { Tukey's } \\
\text { grouping }\end{array}$ & $\begin{array}{c}\% \\
\text { female }\end{array}$ & $\begin{array}{c}\% \text { ơ } 0 \\
\text { blood fed }(n)\end{array}$ & $\begin{array}{c}\% \text { 우 } \\
\text { blood fed }(n)\end{array}$ & $\begin{array}{c}\% \text { 우 } \\
\text { vitellogenic }(n)\end{array}$ \\
\hline BiteFree prototype & $213.6 \pm 99.9$ & A & 37.6 & $55.8(688)$ & $46.0(322)$ & $19.3(322)$ \\
\hline $\begin{array}{c}\text { BiteFree prototype } \\
\text { with Alsynite }\end{array}$ & $204.4 \pm 78.2$ & A & 36.7 & $67.5(536)$ & $60.8(286)$ & $17.1(286)$ \\
\hline Olson & $138.9 \pm 73.5$ & B & 36.2 & $57.8(173)$ & $58.0(81)$ & $23.7(81)$ \\
\hline Broce & $64.8 \pm 35.4$ & $\mathrm{C}$ & 35.4 & $37.3(212)$ & $28.0(118)$ & $11.0(118)$ \\
\hline $\mathrm{Nzi}$ & $14.3 \pm 8.6$ & $\mathrm{D}$ & 33.0 & $81.5(800)$ & $81.2(372)$ & $61.6(372)$ \\
\hline EZ trap & $2.5 \pm 1.9$ & $\mathrm{D}$ & 39.9 & $92.1(76)$ & $16.2(37)$ & $5.4(37)$ \\
\hline Total & & & & $66.3(2,485)$ & $58.4(1,216)$ & $30.8(1,216)$ \\
\hline
\end{tabular}

pellants are frequently washed off by the animals walking through wet grass or standing in ponds.

Traps can be used for both surveillance and local reduction of stable fly populations (Williams 1973, Meifert et al. 1978, Ruff 1979, Gersabeck et al. 1982, Gersabeck and Merritt 1983, Hogsette 1984, Pickens and Hayes 1984). Most stable fly traps are modifications of the adhesive-coated translucent fiberglass panel (Alsynite) trap developed by Williams (1973) . The mechanism of attraction for Alsynite traps is unknown, although it is suspected that flies are attracted to the electromagnetic energy reflected by the panels (Thimijan et al. 1973, Agee and Patterson 1983, Zacks and Loew 1989). More recently, blue/black cloth target-interception traps based upon the Nzi trap developed for tsetse fly (Glossina spp.) control have been suggested for stable fly population monitoring and possibly control (Mihok 2002). The purpose of this study was to compare trapping efficiency and biases of several adhesive trap designs and the Nzi trap.

\section{Materials and Methods}

Traps. Five adhesive traps were included in this study. The Olson trap is a commercially available cylindrical Alsynite trap made from corrugated panels ( 66 by $33.5 \mathrm{~cm}$ in height) formed into a cylinder $20 \mathrm{~cm}$ in diameter with adhesive-treated clear plastic sleeves (Hogsette and Ruff 1990, Olson Products Inc., Medina, OH). The Broce trap (Broce 1988) is a cylindrical Alsynite trap formed from flat Alsynite panels (91.5 by $30.5 \mathrm{~cm}$ in height) formed into a cylinder $28 \mathrm{~cm}$ in diameter. Broce traps were covered with 10-mil SurFlex plastic sleeves (Flex-o-glass, Inc., Chicago, IL) coated with Tangle-Trap (The Tanglefoot Co., Grand Rapids, MI) diluted 1:1 with low-odor paint thinner (Sunnyside Corp., Wheeling, IL). The Farnam BiteFree (Phoenix, AZ) prototype trap is constructed of clear, polyethylene terephthalate (PET), adhesivetreated plastic $(16.3 \mathrm{~cm}$ in diameter by $34.7 \mathrm{~cm}$ in height). The BiteFree prototype trap was tested with and without 2- by 29-cm strips of Alsynite attached to the central hub between the spokes of the trap. The Farnam EZ Trap was constructed of yellow adhesivetreated plastic $(12.7 \mathrm{~cm}$ in diameter by $15.2 \mathrm{~cm}$ in height). All adhesive traps were placed on stakes with the top of the trap $100 \mathrm{~cm}$ above the ground. Nzi traps were purchased from Vestergaard Frandsen (Kolding, Denmark) and constructed from $100 \%$ polyester cloth.
Experimental Design. The experiment was conducted in a field $\approx 100 \mathrm{~m}$ east of the feedlot at the University of Nebraska Agricultural Research and Development Center, Ithaca, NE. Three replicate groups of traps separated by $100 \mathrm{~m}$ were used. Each group consisted of four Nzi traps in the middle facing each ordinal direction. Ten meters east and west of the center of the Nzi traps, a linear transect consisting of each of the five types of adhesive traps was placed in a predetermined random order. Traps were separated by $10 \mathrm{~m}$. Traps were initially placed on 12 July 2004 and then collected and replaced on 14 July, 16 July, and 19 July. Hence, for each of the adhesive traps, there were three groups with two replicates per group and three collections, two representing 48 -h collecting periods and one representing a 72-h collecting period. All data were converted to a per day basis.

Stable flies that were alive at the time of collection were dissected to determine whether they had remnants of a bloodmeal in their gut and whether females were previtellogenic or vitellogenic.

Weather data were collected by the High Plains Regional Climate Center (University of NebraskaLincoln) MEADTURFFARM station located $5 \mathrm{~km}$ northeast of the study location. Hourly wind speeds and directions from the database from 1000 to 1600 hours were averaged to give the reported data.

Data Analysis. Factorial analysis of variance (ANOVA) was used to analyze trap collection data expressed as number of flies collected per day. Means were compared using Tukey's studentized range test. Sex ratio and blood-feeding and vitellogenic rates are presented as percentages. These data were transformed with an arcsine square-root transformation before ANOVA. Because of the necessity to use percentage data for blood feeding and vitellogenic development and the small number of flies collected on some of the traps, these values were pooled by group and by collection for separate analyses. The two analyses did not differ in their conclusions, so only the pooled by collection date analysis is presented. Values of $P<0.05$ were considered significant. All analyses were done with SAS, version 9.1 (SAS Institute 2004).

\section{Results}

The BiteFree prototype traps collected $>3$ times as many flies as the Broce traps and almost twice as many flies as the Olson traps (Table 1). The ratio of males 
Table 2. Directionality of Nzi trap collections

\begin{tabular}{lcc}
\hline Direction & $\begin{array}{c}\text { Mean no. flies } \\
(\text { mean } \pm \text { SD) }\end{array}$ & $\begin{array}{c}\text { Tukey's } \\
\text { grouping }\end{array}$ \\
\hline South & $19.4 \pm 8.8$ & A \\
East & $17.8 \pm 10.9$ & A \\
North & $11.1 \pm 5.2$ & B \\
West & $9.0 \pm 3.8$ & B \\
\hline
\end{tabular}

to females was $\approx 2: 1$ and did not differ among traps $(F=0.46 ; \mathrm{df}=5,119 ; P=0.81)$. Collections varied significantly by date $(F=17.73$; df $=2,116 ; P<$ $0.0001)$, trap type $(F=76.82 ; \mathrm{df}=5,116 ; P<0.0001)$, and group $(F=6.73 ; \mathrm{df}=2,116 ; P=0.017)$. Alsynite inserts did not increase collections on the BiteFree prototype traps. Excluding the Nzi traps because they were located in the centers of each group, no differences were observed between the traps on the east and west sides of the groups $(F=0.54 ; \mathrm{df}=1,70 ; P=$ $0.4650)$. Considering only the Nzi traps, number of stable flies collected per trap day on each of the three collection dates did not differ $(F=3.07$; $\mathrm{df}=2,16 ; P=$ $0.0744)$ whereas differences between groups $(F=$ $10.52 ; \mathrm{df}=2,16 ; P=0.0012)$ and direction the trap was facing $(F=11.24$; df $=3,16 ; P=0.0003)$ were significant. The interaction between date and direction was insignificant $(F=0.35 ; \mathrm{df}=6,16 ; P=0.9005)$. Nzi traps facing south and east collected nearly twice as many stable flies as the traps facing north and west (Table 2). Winds were light and directions variable during the study (Table 3). The interaction between date and direction was not significant $(F=0.35$; $\mathrm{df}=$ $6,16 ; P=0.9005)$. Overall $66 \%$ of male stable flies and $58 \%$ of females had remnants of bloodmeals in their guts. Thirty-one percent of the females were vitellogenic, all of which had remnants of blood in their gut.

\section{Discussion}

The adhesive traps in this study all seem to be sampling the same component of the stable fly population. These traps were biased toward males by a ratio of $\approx 2: 1$. This differs from Hogsette and Ruff (1990) who found the sex ratio to be closer to $1: 1$ on cylindrical traps compared with 1:2 on Williams (1973) traps. The physiological status of the collected flies was similar among the sticky traps as well. Nzi traps seem to be collecting an older component of the stable fly population than the adhesive traps but remained biased toward males at approximately a 2:1 ratio.

The BiteFree prototype traps were $2-3$ times more efficient than the Alsynite-based traps, and the addition of Alsynite strips did not improve their efficiency. The mechanism of attraction and biases of Alsynite traps remain unclear. Zacks and Loew (1989) indicate that the attraction seems to be due to the particular ratio of blue verses red to yellow light transmitted when the Alsynite sheet is approached from an indirect angle. Although many authors have speculated as to the ecological correlate of Alsynite, this also remains unclear. The PET plastic from which the Bite-
Free prototype trap is constructed is unrelated to Alsynite. An understanding of the attractiveness of this second material to stable flies may help in determining the mode of attraction of Alsynite. A peculiarity of the BiteFree prototype traps is the method by which the glue is applied. Rather than being applied in a smooth even coat, the glue is applied in a series of closely spaced lines. When viewed from an angle, the traps seem to sparkle. This appearance could be similar to the off angle interference patterns observed by Zacks and Loew (1989) in the Alsynite panels or to the Moiré patterns noted to be attractive to stable flies by Pickens (1991).

Although similar, the Broce and Olson traps differed in a couple of aspects. The Olson traps were constructed of corrugated Alsynite verses flat Alsynite used for the Broce traps. Also, the sleeves used with the Olson traps were much thinner than the Sur-Flex sleeves used for the Broce traps; and finally, the Olson trap sleeves were preglued, whereas Tangle-Trap was used on the Broce traps. Previous studies have noted significant effects of the types of glue and sleeves used on Alsynite traps on the number of flies collected (Pickens and Hayes 1984, Hogsette and Ruff 1990). We observed that flies were more difficult to remove from the Olson traps than the Broce traps. Further studies are needed to determine which of these aspects accounts for the reduced collections on the Broce traps; however, different glues would be the primary candidate for consideration.

The EZ trap was ineffective for trapping stable flies. They collected $\approx 1 \%$ of the number of flies collected by the BiteFree prototype traps. These traps are constructed of opaque yellow plastic, and the glue was applied as an even film. The glue on the EZ traps was very rubbery making removal of flies for sexing and dissection nearly impossible. Therefore, fewer flies from these traps were dissected than from the others.

Nzi traps were less efficient for trapping stable flies than the Alsynite and BiteFree prototype adhesive traps. However, the Nzi traps do seem to collect an older cohort of the stable fly population compared with those traps. This characteristic may prove useful for dispersion studies where Alsynite traps seem to be biased toward young, preblood-fed flies. One disadvantage of the Nzi traps was that we had considerable problems with grasshoppers (Orthoptera: Acrididae) chewing holes in the netting of the traps. By the end of $6 \mathrm{wk}$, the traps were patched to the point of being

Table 3. Predominant wind direction and speed between 1000 and 1600 hours

\begin{tabular}{lrcrrr}
\hline \hline \multirow{2}{*}{ Date } & \multicolumn{2}{c}{ Direction } & & \multicolumn{2}{c}{ Speed $(\mathrm{km} / \mathrm{h})$} \\
\cline { 2 - 3 } \cline { 5 - 6 } & Avg & Range & & Avg & Range \\
\hline 12 July & 135 & $83-159$ & & 15 & $9-18$ \\
13 July & 24 & $1-19$ & 10 & $7-15$ \\
14 July & 258 & $107-5$ & 8 & $6-10$ \\
15 July & 157 & $121-174$ & & 11 & $7-14$ \\
16 July & 3 & $350-4$ & & 15 & $12-17$ \\
17 July & 28 & $16-68$ & & 8 & $5-10$ \\
18 July & 178 & $164-190$ & & 12 & $10-13$ \\
\hline
\end{tabular}


nearly destroyed. The constant maintenance needed to keep the Nzi traps operational makes their routine use in the field difficult. The cause of the directional bias of the Nzi traps is unclear. Stable flies are known to orient into the wind when following host odors. However, the variability in the wind direction across the days of this study and lack of a significant interaction between day and direction would indicate that orientation to the wind was not the cause of the bias toward the traps facing south and east. The feedlot was to the west of the trap sites so that an orientation toward the feedlot could be responsible for the larger number of flies observed in the east-facing traps. However, the feedlot extended well to the north and south of the study site, so orientation toward the lot could not account for the larger number of flies observed in the south facing traps. The directional bias of the Nzi traps does indicate that it may be possible to use Nzi traps to determine directional movement of stable flies. This information would be helpful for dispersal studies.

\section{Acknowledgments}

Samples of the BiteFree prototype and EZ traps were provided by William Warner of Farnam Company, Inc. Brad Voelker and Steve Herdzina provided technical support. This work was done in cooperation with the Institute of Agriculture and Natural Resources, University of Nebraska-Lincoln and is published as Journal Series, Nebraska Agricultural Research Division paper 15059.

\section{References Cited}

Agee, H. R., and R. S. Patterson. 1983. Spectral sensitivity of stable, face, and horn flies and behavioral responses of stable flies to visual traps. Environ. Entomol. 12: 18231828 .

Broce, A. B. 1988. An improved Alsynite trap for stable flies, Stomoxys calcitrans (Diptera: Muscidae). J. Med. Entomol. 25: 406-409.

Broce, A. B. 1993. Dispersal of house flies and stable flies, pp. 61-69. In G. D. Thomas and S. R. Skoda [eds. ], Rural flies in the urban environment. Nebr. Agric. Exp. Sta. Res. Bull. 317, N. Cent. Reg. Res. Bull. 335.

Campbell, J. B., S. R. Skoda, D. R. Berkebile, D. J. Boxler, G. D. Thomas, D. C. Adams, and R. Davis. 2001. Effects of stable flies (Diptera: Muscidae) on weight gains of grazing yearling cattle. J. Econ. Entomol. 94: 780-783.

Gersabeck, E. F., and R. W. Merritt. 1983. Vertical and temporal aspects of Alsynite panel sampling for adult Stomoxys calcitrans, Diptera: Muscidae. Fla. Entomol. 66: 222-227.

Gersabeck, E. F., R. W. Merritt, and J. D. Haefner. 1982. An efficient trap for collecting wild adult stable flies, Stomoxys calcitrans (Diptera: Muscidae) for mark-release studies. J. Med. Entomol. 19: 541-544.

Haines, T. W. 1953. Breeding media of common flies. I. In urban areas. Am. J. Trop. Med. Hyg. 2: 933-940.

Haines, T. W. 1955. Breeding media of common flies. II. In rural areas. Am. J. Trop. Med. Hyg. 4: 1125-1130.

Hall, R. D., G. D. Thomas, and C. E. Morgan. 1982. Stable fly, Stomoxys calcitrans (L.), breeding in large round hay bales: initial associations (Diptera: Muscidae). J. Kans. Entomol. Soc. 55: 617-620.
Hansens, E. J. 1951. The stable fly and its effect on seashore recreational areas in New Jersey. J. Econ. Entomol. 44: $482-487$.

Hogsette, J. A. 1984. Effect of fluorescent dust color on the attractiveness of attractant self marking devices to the stable fly, Stomoxys calcitrans, Diptera: Muscidae. J. Econ. Entomol. 77: 130-132.

Hogsette, J. A., and J. P. Ruff. 1985. Stable fly (Diptera: Muscidae) migration in northwest Florida. Environ. Entomol. 14: 170-175.

Hogsette, J. A., and J. P. Ruff. 1990. Comparative attraction of four different fiberglass traps to various age and sex classes of stable fly (Diptera: Muscidae) adults. J. Econ. Entomol. 83: 883-886.

Hogsette, J. A., J. P. Ruff, and C. J. Jones. 1987. Stable fly biology and control in Northwest Florida. J. Agric. Entomol. 4: 1-11.

Kunz, S. E., K. D. Murrell, G. Lambert, L. F. James, and C. E. Terrill. 1991. Estimated losses of livestock to pests, pp. 69-98. In D. Pimentel [ed.]. CRC handbook of pest management in agriculture. Volume I. CRC, Boca Raton, FL.

Lysyk, T. J. 1993. Adult resting and larval developmental sites of stable flies and house flies (Diptera: Muscidae) on dairies in Alberta. J. Econ. Entomol. 86: 1746-1753.

Mihok, S. 2002. The development of a multipurpose trap (the Nzi) for tsetse and other biting flies. Bull. Entomol. Res. 92: 385-403.

Meifert, D. W., R. S. Patterson, T. Whitfield, G. C. LaBrecque, and D. E. Weidhass. 1978. Unique attractanttoxicant system to control stable fly populations. J. Econ. Entomol. 71: 290-292.

Meyer, J. A., and J. J. Petersen. 1983. Characterization and seasonal distribution of breeding sites of stable flies and house flies (Diptera: Muscidae) on eastern Nebraska feedlot and dairies. J. Econ. Entomol. 76: 103-108.

Newson, H. D. 1977. Arthropod problems in recreational areas. Annu. Rev. Entomol. 22: 333-353.

Pickard, E. 1968. Stomoxys calcitrans (L.) breeding along TVA reservoir shorelines. Mosq. News 28: 644-646.

Pickens, L. G. 1991. Battery-powered, electrocuting trap for stable flies (Diptera: Muscidae). J. Med. Entomol. 28: 822-830.

Pickens, L. G., and D. K. Hayes. 1984. Evaluation of a new face fly, Musca autumnalis, and stable fly, Stomoxys calcitrans, Muscidae, trap which segregates the catch of the 2 species. Environ. Entomol. 13: 1256-1260.

Ruff, J. P. 1979. Trapping effectiveness of several combinations of colors and textures of sticky traps for stable flies, Stomoxys calcitrans. Mosq. News 39: 290-292.

SAS Institute. 2004. SAS 9.1.3 help and documentation. SAS Institute, Cary, NC

Scholl, P. J., J. J. Petersen, D. A. Stage, and J. A. Meyer. 1981. Open silage as an overwintering site for immature stable flies in eastern Nebraska. Southwest. Entomol. 6: 253-258.

Simmons, S. W., and W. E. Dove. 1941. Breeding places of the stable fly or "dog fly" Stomoxys calcitrans (L.) in northwestern Florida. Fla. Antimosq. Assoc. Rep. 15: 6264.

Skoda, S. R., and G. D. Thomas. 1993. Breeding sites of stable flies and house flies, pp. 61-69. In G. D. Thomas and S. R. Skoda [eds.], Rural flies in the urban environment. Nebr. Agric. Exp. Sta. Res. Bull. 317, N. Cent. Reg. Res. Bull. 335 .

Skoda, S. R., G. D. Thomas, and J. B. Campbell. 1991. Developmental sites and relative abundance of immature stages of the stable fly (Diptera: Muscidae) in beef cattle feedlot pens in eastern Nebraska. J. Econ. Entomol. 84: 191-197. 
Thimijan, R. W., L. G. Pickens, and N. O. Morgan. 1973. Responses of the house fly, stable fly, and face fly to electromagnetic radiant energy. J. Econ. Entomol. 66: 1269-1270.

[USDA-NASS]U.S. Department of Agriculture-National Agriculture Statistics Service. 2006. Livestock slaughter 2005 summary. U.S. Dep. Agric., Washington, DC.

Voegtline, A. C., G. W. Ozburn, and G. D. Gill. 1965. The relation of weather to biting activity of Stomoxys calcitrans (L.) along Lake Superior. Papers Mich. Acad. Sci. Arts Lett. 50: 107-114.
Ware, G. W. 1966. Power-mower flies. J. Econ. Entomol. 59: 477-478.

Williams, D. F. 1973. Sticky traps for sampling populations of Stomoxys calcitrans. J. Econ. Entomol. 66: 1274-1280.

Williams, D. F., A. J. Rogers, and P. Hester. 1980. Preferred breeding media of the stable fly in northwestern Florida. Mosq. News 40: 276-279.

Zacks, D. N., and E. R. Loew. 1989. Why is Alsynite fiberglass sheet attractive to stable flies? Exp. Biol. 48: 215-222.

Received 12 January 2006; accepted 26 April 2006. 